\title{
REACH compliant epoxides used in the synthesis of Fe(III)-based aerogel monoliths for target fabrication
}

\author{
Alberto Valls Arrufat ${ }^{1}$, Magdalena Budziszewska ${ }^{1}$, Clement Lopez ${ }^{1}$, Aymeric Nguyen ${ }^{1}$, \\ Jakub Sitek $^{1}$, Paul Jones ${ }^{1}$, Chris Shaw ${ }^{1}$, Ian Hayes ${ }^{2}$, Gareth Cairns ${ }^{2}$, \\ and Glenn Leighton ${ }^{1}$ \\ ${ }^{1}$ Surface Engineering and Nanotechnology Institute, School of Aerospace, Transport and Manufacturing, Cranfield University, Milton \\ Keynes, Bedfordshire, MK43 OAL, UK \\ ${ }^{2}$ Target Fabrication Group, AWE, Aldermaston, Reading, Berkshire, RG7 4PR, UK \\ (Received 7 November 2016; revised 5 July 2017; accepted 22 August 2017)
}

\begin{abstract}
Aerogel materials manufactured from metal oxides have been used as components in numerous high-energy density physics targets. These aerogels have been identified to be used as a future target material in the AWE fielded campaigns at the US National Ignition Facility. A wide variety of metal oxide aerogels are required for future campaigns and therefore a versatile manufacturing route is sought; as such, an epoxide-assisted sol-gel route was investigated. Under the European Union Registration, Evaluation, Authorization and Restriction of Chemicals legislation, the most commonly used epoxide, propylene oxide, is recognized as a substance of very high concern (SVHC). This work sought to investigate suitable alternative epoxides for use in target manufacture. The outcome was the identification of synthesis routes for stable metal oxide aerogel monoliths using epoxides not subject to the above restrictions.
\end{abstract}

Keywords: aerogel; epoxide; metal oxide; sol-gel; SVHC

\section{Introduction}

Aerogel materials have found many potential applications due to their very specific properties ${ }^{[1]}$ : thermal barriers, catalytic surfaces, lightweight optics, range finders, speakers, energy absorbers and capacitors. Aerogel materials have also been used as a component in many designs for high-energy density (HED) physics targets. For example, aerogels offer the ability to have low density, with the potential for uniform porosity, optically thick components in HED experiments, without the problem of relatively large pore sizes as found in pure metal foams.

Metal oxide aerogels have been more challenging to synthesize and are less well understood than the silica type ${ }^{[2]}$, especially when these aerogels have been formed via catalyzed hydrolysis and condensation reaction of metal alkoxide precursors ${ }^{[3,4]}$. Unfortunately, the lack of suitable metal alkoxides and their associated handling issues has restricted the production of metal oxide aerogels. However, the epoxide-assisted gelation approach expanded the production

Correspondence to: Dr Glenn Leighton. School of Aerospace, Transport and Manufacturing, Cranfield University, Milton Keynes, Bedfordshire, MK43 0AL, UK. Email: g.j.t.leighton@cranfield.ac.uk of metal oxide aerogels and the range of possible salt precursors that could be used ${ }^{[2]}$. From the literature, propylene oxide (PO) has been well documented as the prime epoxide precursor used to create these metal oxide aerogels ${ }^{[5]}$.

Although the evidence is good and functional aerogel structures have been reported when using PO, the precursor is recognized as a 'substance of very high concern' (SVHC) under the European Union (EU) Registration, Evaluation, Authorization and Restriction of Chemicals ${ }^{[6,7]}$ (REACH) legislation. The remit of REACH is to provide a high level of protection to human health and the environment, regulate the production and movement of chemicals and enhance innovation in the EU chemical industry. Within the REACH legislation there is the SVHC subsection which controls the use of chemicals that are deemed to have serious or irreversible effects on human health and the environment. As such, sanctions on an SVHC-listed chemical can range from limiting general access to a total ban on usage within the EU. Particular emphasis is placed on organizations finding suitable replacements for listed materials, which is why finding a suitable epoxide replacement for PO is of interest.

Creating a sol-gel is usually the first step in the process of aerogel synthesis and involves the crosslinking of particles 
dispersed in a solvent, for example ethanol, to form a nanostructured $(1-100 \mathrm{~nm})$ wet gel ${ }^{[8]}$. More precisely, the gel is a monolithic structure based on covalent bonding forming clusters and crosslinks between clusters. Once the wet gel has formed it is allowed to 'age', often over a period of hours or days, while submerged in a solvent; this allows for all chemical reactions to complete and also for 'clean' solvent to defuse within the gel matrix. This process allows for the removal of any unreacted salts and contaminants, for example water, from the structure. To create the final aerogel, the liquid component is displaced from the wet gel by undertaking solvent exchange with supercritical $\mathrm{CO}_{2}$. In the supercritical state, $\mathrm{CO}_{2}$ has no surface tension when changing from a liquid to gas; thus, when the $\mathrm{CO}_{2}$, which has replaced the original solvent, phase changes to a gas the crosslinked clusters in the gel do not collapse due to capillary forces but keep the same porous structure as the original wet gel.

The type of salt used, chloride or nitrate, has an effect on gelation time where chlorides tend to gelate faster than nitrates ${ }^{[9]}$. The salt used can also affect the structure of the resulting aerogel, a good example being the $\mathrm{FeCl}_{3}$ and $\mathrm{Fe}\left(\mathrm{NO}_{3}\right)_{3}$ salts. Both can produce high-quality $\mathrm{Fe}_{2} \mathrm{O}_{3}$ aerogels, and it was found by Gash et al. ${ }^{[10]}$ that chloride salts gave a monolith with a greater surface area and largerpore diameters compared to the nitrate $\left(390 \mathrm{~m}^{2} / \mathrm{g}\right.$ and $23 \mathrm{~nm}$ compared to $340 \mathrm{~m}^{2} / \mathrm{g}$ and $12 \mathrm{~nm}$ ). It was also observed that for alumina aerogels the structure was affected by the salt used ${ }^{[11]}$; for nitrate salts the structure was seen to be made up of individual particles that connected to form an open multiclustered structure while the chloride produced a fibrous arrangement. Another influence on structure is the epoxide used ${ }^{[5,12]}$; for example, it has been seen that particle sizes can vary greatly ${ }^{[13,14]}$. The solvent used can also affect the final aerogel; where water is used aerogels tend to have lower density and the initial reaction is slower compared to when ethanol is used. Alternately, when ethanol is used the final aerogel can experience some shrinkage but can give a less-fragile and easier-to-handle monolith ${ }^{[11]}$. The synthesis of the aerogel is therefore a balance of these three components: salt (nitrate or chloride), solvent and epoxide. In this work, we present an Fe(III) aerogel synthesis route using epoxides other than PO which are not listed in the SVHC candidate list.

\section{Methodology}

Absolute ethanol (200 proof, Arcos Organic), methanol (SLR, Fisher Chemical) and distilled water were used as solvents. The epoxides were PO (99.5\%, Arcos), trimethylene oxide (TO), (98\%, Fisher Chemical), 1,2-epoxybutane (EB), (99\%, Sigma-Aldrich) and cyclohexene oxide, (98\%, SigmaAldrich). The iron salts were iron(III) nitrate nonahydrate
Table 1. Example formulation used for formation of Fe(III)-based aerogels.

\begin{tabular}{ll}
\hline Reactants & Quantity \\
\hline Iron (III) chloride hexahydrate & $0.541 \mathrm{~g}$ \\
Ethanol & $5 \mathrm{~mL}$ \\
TO & $1.431 \mathrm{~mL}$ \\
Water & $0.108 \mathrm{~mL}$ \\
\hline
\end{tabular}

(98\%, Alfa Aesar) and iron(III) chloride hexahydrate (98\%, Sigma-Aldrich).

The relevant quantities of salt (11:1 molar ratio epoxide to salt) were dissolved in the required solvent in a flat bottom flask using a magnetic mixer at ambient temperature. Once all the salt dissolved, it was transferred to a mould. The candidate epoxide was mixed with the appropriate quantity of solvent and then added to the salt solution in the mould using a pipette. The reaction process was left to continue until a gel had formed, at which point it was left to age for 12-24 h with frequent solvent exchange taking place using ethanol. The aged gels were removed from the moulds and placed in to open top polytetrafluoroethylene (PTFE) pots containing ethanol. One formulation used as part of this paper is shown in Table 1.

The method used for the synthesis is as follows

- Mix the $2.5 \mathrm{~mL}$ of ethanol with the salt in the beaker, stir until complete dissolution and add the $0.108 \mathrm{~mL}$ of water. Cover to avoid ethanol evaporation.

- Add $2.5 \mathrm{~mL}$ of ethanol to the syringe and then add $1.431 \mathrm{~mL}$ of epoxide, stir together in the syringe.

- Dropwise (drop/2 S) add solution of salt and ethanol to the solution of epoxide and ethanol.

- Quickly cover to avoid ethanol evaporation.

- Gelation will occur in no longer than $24 \mathrm{~h}$. Store the syringe in a place avoiding vibration.

- After gelation age the gel for $48 \mathrm{~h}$.

- Unmould the gel into a PTFE beaker.

- After unmoulding, add ethanol.

- Beaker with gel and ethanol should be supercritically dried, in $\mathrm{CO}_{2}$ for $72 \mathrm{~h}$ to ensure full solvent exchange.

Aerogel drying was undertaken using supercritical $\mathrm{CO}_{2}$ at $150 \mathrm{bar}$, with a pump rate of $1 \mathrm{~g} / \mathrm{min}$ over a period of 3-4 days, a high-volume purge of 50 bar being carried out once a day to aid in the solvent exchange process. Once the drying cycle was completed, dropping 1 bar every $60 \mathrm{~s}$ to atmosphere, the samples were removed and stored in sealed glass bottles ready for characterizing. Characterization was undertaken using a Philips XL30 SFEG scanning electron microscope (SEM) and sample weights being measured using an OHAUS Pioneer precision balance. 


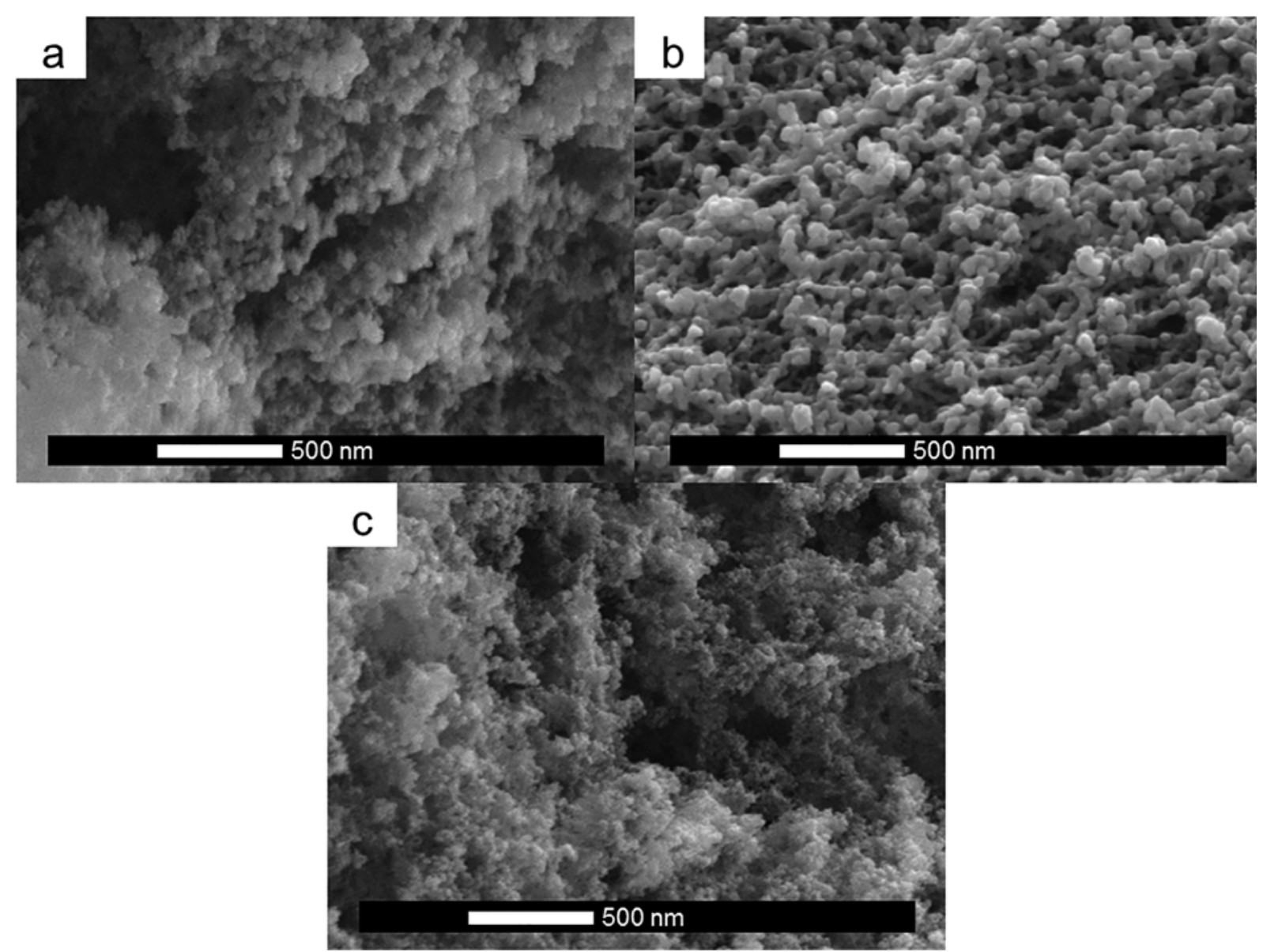

Figure 1. SEMs showing the microstructure of Fe(III)-based aerogels created using nitrate salts, ethanol and the epoxides (a) PO; (b) EB; (c) TO.

\section{Results and Discussion}

SEMs of Fe(III)-based aerogels with nitrate precursor using the PO, EB and TO epoxides are shown for comparison in Figure 1(a)-(c) and the average density, pore size and particle size are tabulated in Table 2. It can be seen that the choice of epoxide has a definite effect on the resulting structure of the aerogel. The PO sample [Figure 1(a)], is used here as a reference as this is the epoxide that is being replaced by the other candidates. At the macroscale, the resultant PO aerogel [Figure 2(a)] was not of a high quality, being relatively weak and having a tendency to crumble into powder when handled and thus a poor candidate for target manufacture. On closer inspection it can be seen that though the average particle size was $70 \mathrm{~nm}$ they formed clusters of clusters, some larger than $1 \mu \mathrm{m}$ [Figure 2(b)]. This clustering has an impact on both the density and porosity of the sample and as evidenced by the powdering on handling, it also impacts on strength.

Compared to the PO aerogel, the EB and TO samples, did not suffer from the same level of clustering and all had a lower average density and particle size as can be seen in Table 2. Of particular note are the higher levels of porosity
Table 2. Average density, pore size and particle size for each epoxides used.

\begin{tabular}{llll}
\hline Epoxide & $\begin{array}{l}\text { Average } \\
\text { density } \\
{\left[\mathrm{mg} / \mathrm{cm}^{3}\right]}\end{array}$ & $\begin{array}{l}\text { Average } \\
\text { pore size } \\
{[\mathrm{nm}]}\end{array}$ & $\begin{array}{l}\text { Average } \\
\text { particle size } \\
{[\mathrm{nm}]}\end{array}$ \\
\hline PO & 118 & N/A & 70 \\
EB & 97 & 109 & 57 \\
TO & 86 & 179 & 62 \\
Cyclohexane oxide* & 101 & 45 & 33 \\
\hline
\end{tabular}

* Cyclohexane using chloride salt, all others nitrate.

for the EB and TO samples with pore size in the range of 109 and $179 \mathrm{~nm}$, respectively; their densities are also lower at 97 and $86 \mathrm{~nm}$. While an attempt was made to synthesize an aerogel using the cyclohexene oxide, $\mathrm{CO}$, with the nitrate salts and ethanol it was found that the mixture was highly exothermic and a gel did not form. This did not occur with the chloride salt and methanol process (Figure 3) though this created a denser aerogel with smaller pore and particle size compared to the EB and TO. It is not possible to differentiate whether this is due to the influence of the epoxide or the salt. The type of epoxide used also had an effect on gelation time, Table 3. The PO had the fastest gelation in the order of tens 


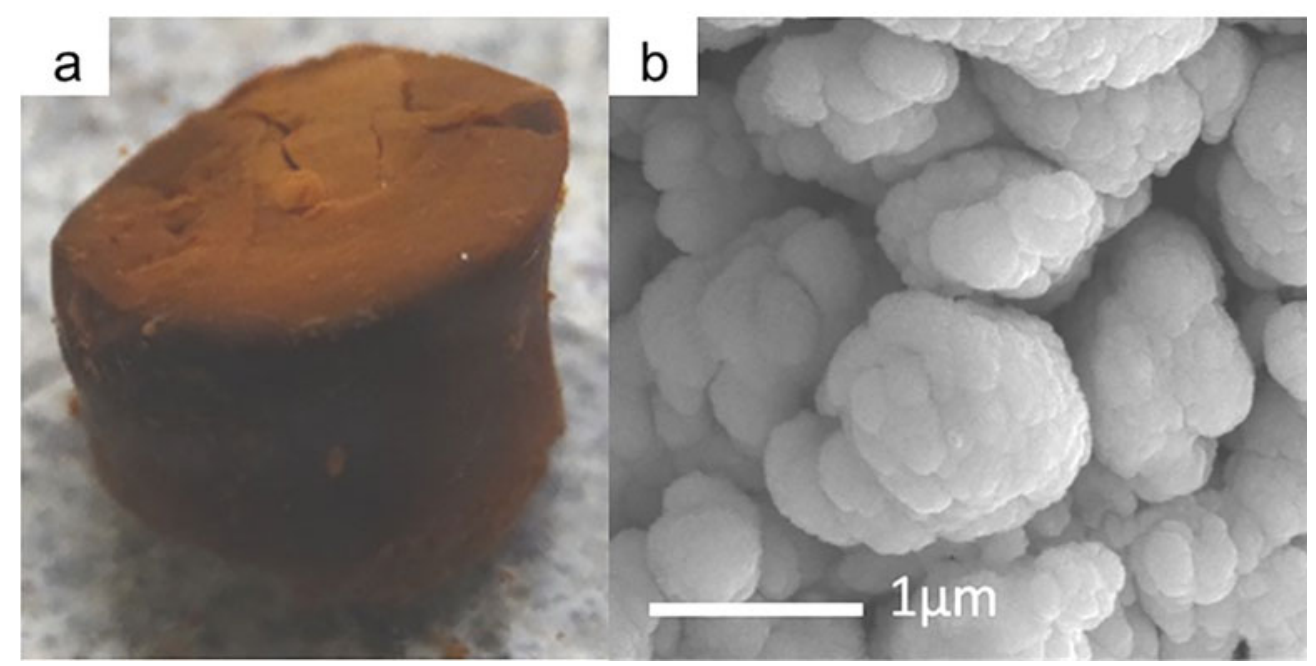

Figure 2. Fe (III)-based aerogel synthesized using PO (a) monolith, (b) SEM showing the larger clusters are made up of nanoparticles in the 70-100 nm range.

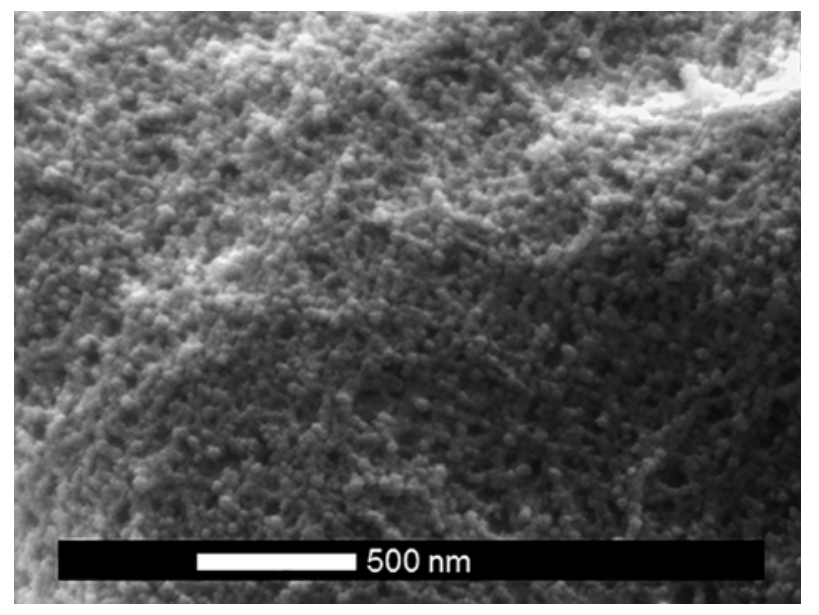

Figure 3. SEM microstructure of cyclohexene oxide aerogel, created using chloride salt and methanol.

Table 3. Average Gelation times for epoxides used across the breath of salts used.

\begin{tabular}{ll}
\hline Epoxide & $\begin{array}{l}\text { Average gelation time } \\
{[\mathrm{min}]}\end{array}$ \\
\hline PO & 0.3 \\
EB & 3 \\
TO & 30 \\
Cyclohexene oxide & 900 \\
\hline
\end{tabular}

of seconds, followed by the EB and TO, while the longest time taken was the $\mathrm{CO}$ where it took over $15 \mathrm{~h}$ for a gel to form, with the time taken for the gel being estimated through observation of the mixture of solutions.

There was also a noticeable difference in aerogel structure when either nitrate or chloride salts were used. A good example of this can be seen in Figure 4 for the TO epoxide

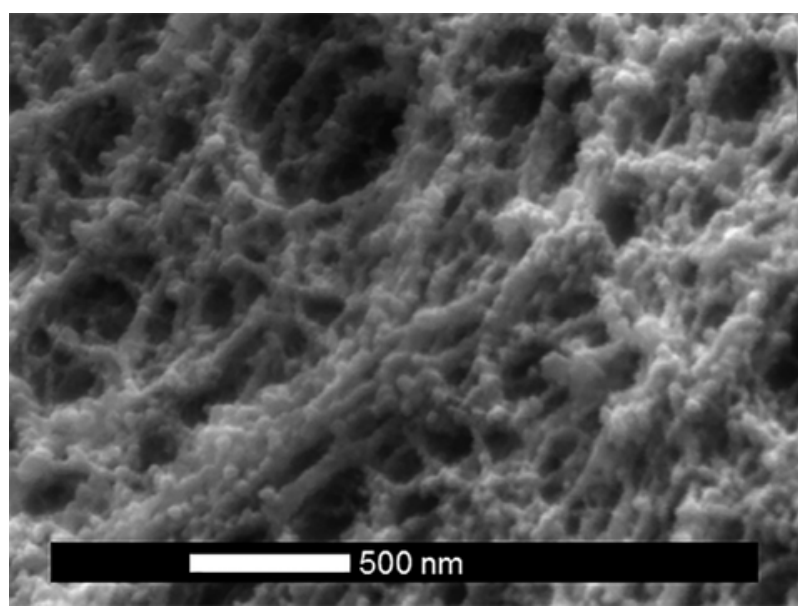

Figure 4. SEM micrograph of an Fe (III)-based aerogel using iron(III) chloride hexahydrate and TO.

process using the chloride salt which gave a more porous structure $15 \%$ greater than the nitrate [Figure 1(c)] determined by sizing of pores and particles using assessment of the SEM micrographs. The monoliths produced using the chloride salts were of a high quality (Figure 5), but were not as low in density as the monoliths produced with the nitrate salts; due to structure of the resulting aerogels, the chloride aerogels gave rise to aerogels with greater density having little visible particles while the nitrate aerogels were lighter with more spherical particles which were highly linked. Also of interest is that the nitrate precursors tended to give rise to more amorphous aerogels while chloride salts led to more fibrous ones.

One of the parameters that were investigated during the synthesis process was how the ratio of solvent used with the epoxide to that in the initial salt solution affected the quality 


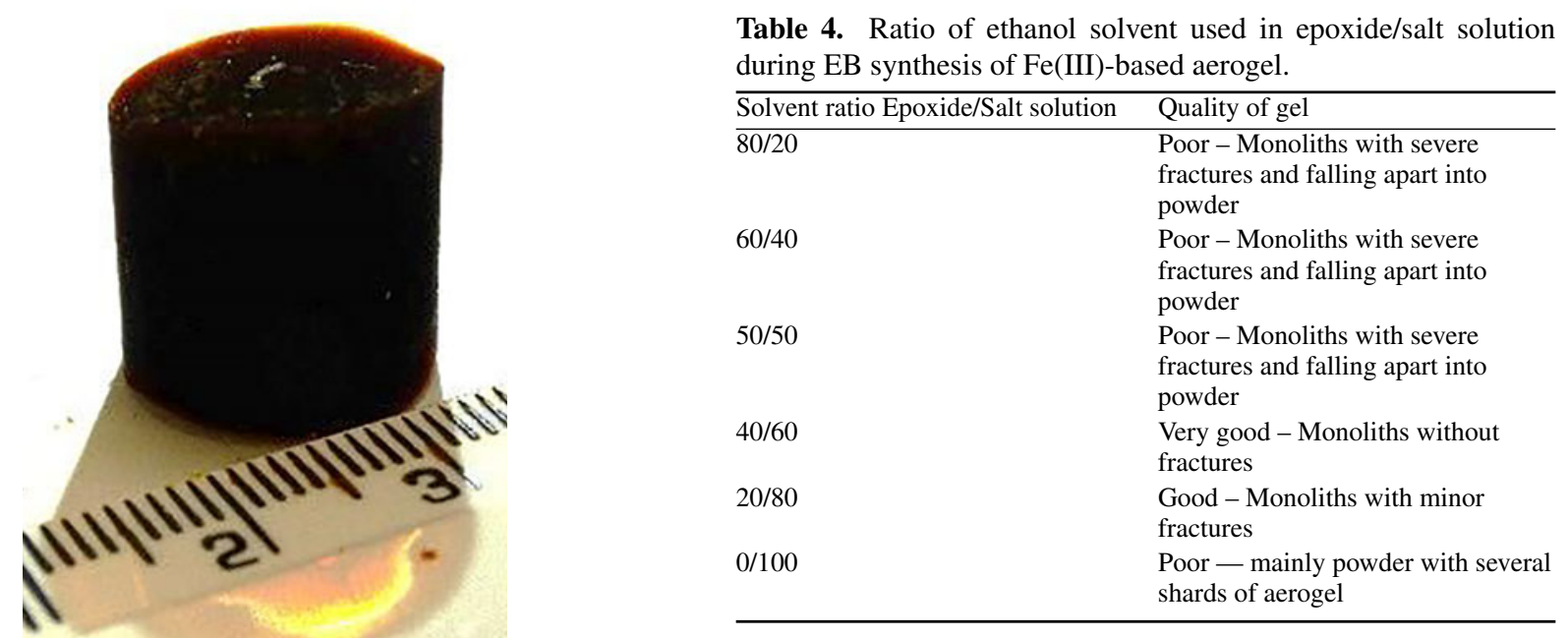

Figure 5. Fe(III)-based aerogel monolith using iron(III) chloride hexahydrate and TO.

of the final aerogel. It should also be noted that some of the exothermic reactions were lessened when the solvent was distributed between the salt and epoxide solutions. Table 4 shows a qualitative description for various ratios from $80 / 20$ to $0 / 100$ solvent in epoxide/salt for the synthesis of EB. It can be seen that mixing $40 \%$ of the solvent into the epoxide and $60 \%$ into the salt solution gave the highestquality aerogel. Alternatively, mixing all the solvent into the salt and then adding the epoxide gave a very poor result; mainly powder with a few shards of $400 \mu \mathrm{m}$ or less. The poor results observed when there is no initial addition of solvent to the epoxide could be due to the existence of a concentration gradient as the epoxide is added to the salt solution. This could lead to a rapid reaction occurring at the interface between the two solutions where the shards are formed, the reaction then slowing as the reactants get used up. Therefore, having the epoxide partially diluted with solvent may allow better mixing and thus allow the formation of a higher-quality gel network.

Another important parameter is the ratio of epoxide to salt, showing linkage to a variation in pore size. An example of this can be seen for the EB aerogel (Figure 6), where there is an increase in pore size in Figure 6(a) using $2 \mathrm{~mL}$ of epoxide compared to Figure 6(b) using $3 \mathrm{~mL}$, both with the same quantity of salt. This variation could be linked to the gelation time as shown in Table 5, the larger pores being set in the structure of the gel when gelation is fast, and smaller ones being formed over a longer period for the slower.

From these investigations it can be seen that there is a direct relation between the final aerogel microstructure and the type of epoxide used in synthesis. With an average pore size of $190 \mathrm{~nm}$ across all variations the TO produced a highly porous aerogel while the $\mathrm{EB}$ and $\mathrm{CO}$ gave structures which
Table 4. Ratio of ethanol solvent used in epoxide/salt solution during EB synthesis of Fe(III)-based aerogel.

\begin{tabular}{ll}
\hline Solvent ratio Epoxide/Salt solution & Quality of gel \\
\hline $80 / 20$ & $\begin{array}{l}\text { Poor - Monoliths with severe } \\
\text { fractures and falling apart into } \\
\text { powder }\end{array}$ \\
$60 / 40$ & $\begin{array}{l}\text { Poor - Monoliths with severe } \\
\text { fractures and falling apart into } \\
\text { powder }\end{array}$ \\
& $\begin{array}{l}\text { Poor - Monoliths with severe } \\
\text { fractures and falling apart into } \\
\text { powder }\end{array}$ \\
$50 / 50$ & Very good - Monoliths without \\
fractures \\
Good - Monoliths with minor \\
fractures \\
Poor - mainly powder with several \\
shards of aerogel
\end{tabular}

Table 5. EB Fe (III)-based aerogels gelation time and gel quality comparison.

\begin{tabular}{lll}
\hline $\begin{array}{l}\text { Amount of epoxide } \\
(\mathrm{mL})\end{array}$ & Gel quality & $\begin{array}{l}\text { Gelation time } \\
(\mathrm{min})\end{array}$ \\
\hline 1 & $\begin{array}{l}\text { Poor - mainly powder with } \\
\text { several shards of aerogel }\end{array}$ & 30 \\
2 & $\begin{array}{l}\text { Poor - Monoliths with severe } \\
\text { fractures and falling apart into } \\
\text { powder } \\
\text { Very good - Monoliths without } \\
\text { fractures }\end{array}$ & 5 \\
\hline
\end{tabular}

had higher average densities, explained by the fact that the pore size was much smaller than the TO. The monoliths produced using the TO were also structurally stronger than those produced by the other epoxides, due to the fibrous nature of the resulting aerogel as opposed to the amorphous particles seen in the others.

\section{Conclusion}

This work shows that viable alternatives to PO can be used to create monolithic Fe(III)-based aerogels via an epoxideassisted gelation route, and the identified epoxides do not class as SVHC chemicals under REACH legislation. The combination of the precursor epoxide and iron salt with the solvent system, has been shown to play an important role in affecting the internal morphological structure of the aerogel and the subsequent mechanical strength of the resultant monolith. The best monolithic structures have been achieved by an optimized dilution of the epoxide with solvent before addition to the dissolved salt, which has delivered structures with greater average sized porosity while maintaining mechanical strength. It has not only been seen that the dilution of the epoxide aids the mixing of the precursors, but that also a relatively rapid gelation time is required to achieve the best monoliths. The work 


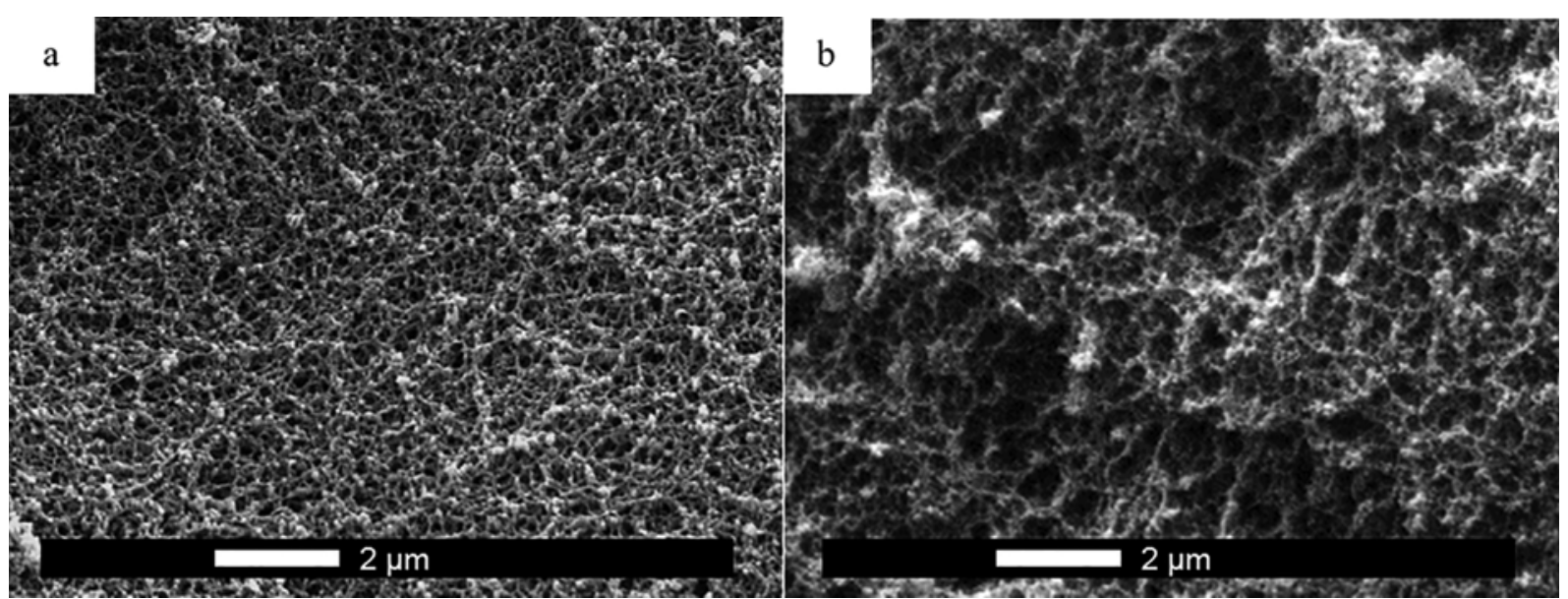

Figure 6. Comparison between EB Fe(III)-based aerogels with different ratios of epoxide to $0.808 \mathrm{~g}$ of iron nitrate salt. (a) 2 and (b) $3 \mathrm{~mL}$.

presented here builds on our understanding of the use of alternative epoxides ${ }^{[10-12]}$ by demonstrating the production of monolithic samples over a greater range of reaction conditions.

\section{Acknowledgements}

This work was funded by AWE, Aldermaston, Reading, Berkshire, RG7 4PR, UK.

\section{References}

1. L. W. Hrubesh, J. Non. Cryst. Solids 225, 335 (1998).

2. M. M. Zhao, S. Manic, M. S. Ruiz-Gonzalez, and F. Koebel, The sol-gel Handbook, 1st ed. M. Levy and D. Zayat (eds) (Wiley, Weihneim, 2015), p. 519.

3. J. F. Poco, J. H. Satcher, and L. W. Hrubesh, J. Non. Cryst. Solids 285, 57 (2001).

4. B. E. Yoldas, J. Mater. Sci. 10, 1856 (1975).
5. A. E. Gash, T. M. Tillotson, J. H. Satcher, Jr, L. W. Hrubesh, and R. L. Simpson, J. Non. Cryst. Solids 285, 22 (2001).

6. Health and Safety Executive - REACH regulations [Online]. Available: http://www.hse.gov.uk/reach/. (Accessed: 12-Apr2016).

7. European Chemicals Agency. [Online]. Available: http://echa. europa.eu/. (Accessed: 12-Apr-2016).

8. A. C. Pierre and G. M. Pajonk, Chem. Rev. 102, 4243 (2002).

9. M. A. Aegerter, N. Leventis, and M. A. Koebel, Aerogels Handbook (Springer, 2011), p. 163.

10. A. E. Gash, T. M. Tillotson, J. H. Satcher, J. F. Poco, L. W. Hrubesh, and R. L. Simpson, Chem. Mater. 13, 999 (2001).

11. T. F. Baumann, A. E. Gash, S. C. Chinn, A. M. Sawvel, R. S. Maxwell, and J. H. Satcher, Chem. Mater. 17, 395 (2005).

12. A. E. Gash, J. H. Satcher, and R. L. Simpson, Chem. Mater. 15, 3268 (2003).

13. J. D. Walker, "Exploring the synthesis and characterization of nanoenergetic materials from sol-gel chemistry exploring the synthesis and characterization of nanoenergetic materials from sol-gel chemistry," PhD. Theses (Georgia Tech., 2007).

14. J. Livage, M. Henry, and C. Sanchez, Prog. Solid State Chem. 18, 259 (1988). 